Results Ninety-one healthy term infants aged 1 to 36 hrs were studied ( $<6$ hrs $-21,6-12$ hrs $-47,13-24$ hrs - 11, and 25-36 hrs 12). A well-developed SWC was evident as early as within the first 6 hrs after birth. The mean (SD) percentage of active sleep (AS) was $52.1 \%$ (12.9), quiet sleep (OS) - 38.6\% (12.5). AS was longer and OS shorter in infants delivered by elective caesarean section (CS) compared to infants delivered by vaginal delivery (AS: $p=0.01$; OS: $p=0.02$ ) or emergency CS (AS: $p=0.04$, $O S$ : $p=0.02$ ). Five infants did not have any SWC present. Disrupted SWCs correlated significantly with the absence of a spontaneous onset of labour $(p=0.03)$.

Conclusion This is the first time that SWC composition has been quantified using EEG monitoring so early in the postnatal period. AS dominates and SWC is clearly present immediately after birth. SWC composition appears to be influenced by labour and mode of delivery.

\section{3D DIGITAL CAPTURE OF HEAD GROWTH IN NEONATES - CORRELATION OF HEAD CIRCUMFERENCE AND HEAD VOLUME}

doi:10.1136/archdischild-2012-302724.1080

W Burkhardt, S Ifflaender, A Koch, M Rüdiger. Department of Neonatology and Paediatric Intensive Care, University Hospital Carl Gustav Carus, Dresden, Germany

Background Head circumference (HC) is measured in newborns to evaluate head growth. It is not known, whether $\mathrm{HC}$ is always an appropriate measure of head volume (HV). Digital capture of the neonatal head offers information on $\mathrm{HC}$ and $\mathrm{HV}$.

Aims To determine

a) overall correlation of $\mathrm{HC}$ and $\mathrm{HV}$ and

b) with regard to postmenstrual age (PMA) and

c) with regard to the actual body weight (BW)

Methods Head measurements with STARscanner laser shape digitizer (Vorum research Corp., Vancouver, BC) were performed in preterm infants prior to discharge over a 12 month period. Data on HC and HV were calculated with STARscanner Laser Data Acquisiton System (Orthomerica, Orlando, FL) and analyzed in different subgroups.

Results Included were 243 neonates at time of discharge (mean HC $32.8 \pm 1.9 \mathrm{~cm}$, mean $H V 356.7 \pm 64.3 \mathrm{ml})$. a) There was an overall correlation between $\mathrm{HC}$ and $\mathrm{HV}\left(r=0.90, R^{2}=0.81, p<0.001\right)$. Correlation between $\mathrm{HC}$ and $\mathrm{HV}$ was: $b)$ in infants with a PMA $<37(r=0.71$, $\left.R^{2}=0.52, p=0.001\right)$ vs. PMA $>37$ weeks $\left(\mathrm{r}=0.92, R^{2}=0.85, p<0.001\right)$ and c) in BW $<2500 \mathrm{~g}\left(r=0.69, R^{2}=0.49, p=0.04\right)$ vs. BW $>2500 \mathrm{~g}(r=0.88$, $\left.R^{2}=0.77, p<0.001\right)$.

Conclusions Neonates with comparable $\mathrm{HC}$ can show very different $\mathrm{HV}$, especially in infants with low PMA or BW. Thus additional measurement of $\mathrm{HV}$ enables to detect variable patterns of head growth and shape. Underlying causes and the meaning for neurological outcome need to be determined.

\section{LEVELS OF SERUM N-TERMINAL PRO-BRAIN NATRIURETIC PEPTIDE, CYSTATIN C, AND URINARY B2 MICROGLOBULIN IN NEWBORNS WITH HYPOXIC ISCHEMIC ENCEPHALOPATHY}

doi:10.1136/archdischild-2012-302724.1081

B Aydin, D Dilli, S Erol, E Ozyazici, S Beken, NE Cullas Ilarslan, A Zenciroglu, N Okumus. Neonatology, Dr Sami Ulus Maternity and Children's Health and Diseases Training and Research Hospital, Ankara, Turkey

Background and Aim Levels of serum N-terminal pro-brain natriuretic peptide (NT-proBNP), cystatin-C ve urinary $\beta 2$ microglobulin in newborns with hypoxic ischemic encephalopathy (HIE) were examined in this study.
Methods In this study, 25 infants diagnosed with HIE were evaluated prospectively. The diagnosis was made according to criterias of American Gynaecelogy and Obstetric Academy (ACOG, 2003). Serum creatinine, NT-proBNP, cystatin $C$ and urinary $\beta 2$ microglobulin in all patients were measured on the 1 st and 5 th days of hospitalization.

Results The mean gestational age was 38.7 weeks and the birth weight was 3255 grams. Patients were classified as stage- $1(n=5)$, stage- $2(n=15)$ and stage- $3(n=5)$ HIE according to Sarnat classification. Therapeutic hypothermia was established in 6 patients. Acute renal failure (ARF) developed in 3 cases with stage 3 HIE. Peritoneal dialysis was performed for 2 of them. First day serum creatinine levels were higher than the 5 th day levels $(p=0.01)$. NT-proBNP and cystatin-C levels was significantly lower on the fifth day $(p=0.01)$. Although not statistically significant, urinary $\beta 2$ microglobulin (mg/g cre) levels on the 1st day were higher than the 5 th day $(\mathrm{p}=0.40)$. On the first day of hospitalization, a statistically significant correlation between NT-proBNP and creatinine $(p=0.02)$, cystatin- $C(p=0.01)$ and urinary $\beta 2$ microglobulin levels $(p=0.01)$ were determined. NT-proBNP and cystatin-C levels were significantly high on the first day in infants developing ARF.

Conclusion It may be beneficial to evaluate serum $\mathrm{N}$-terminal proBNP ve cystatin-C with creatinin levels in HIE patients for the diagnosis, severity and follow-up of ARF.

\section{BLOOD PRESSURE AND AMPLITUDE INTEGRATED ELECTROENCEPHALOGRAPHY CORRELATIONS IN FULL TERM NEONATES WITH HYPOXIC ISCHAEMIC ENCEPHALOPATHY}

doi:10.1136/archdischild-2012-302724.1082

'M Krasovitsky, ${ }^{1,2 Z}$ Kecskes. 'Medical School, Australian National University, Canberra; ${ }^{2}$ Department of Neonatology, Canberra Hospital, Woden, ACT, Australia

Background The correlation between systemic blood pressure (BP) and amplitude integrated electroencephalography (aEEG) in full term neonates with hypoxic ischaemic encephalopathy (HIE) is clinically complex, affecting therapy and prognosis.

Method Term infants with HIE and $<48$ hours of age were identified from a prospectively kept database. Mean (MAP), systolic and diastolic blood pressure was recorded over a four hour period. aEEG patterns and corresponding output (in $\mu \mathrm{V}$ ) of crosshead, right and left leads over the same period were recorded and analysed. The cohort was analysed according to a range of variables including treatment or non-treatment of hypotension and degree of encephalopathy.

Results Twenty-nine episodes of hypotension experienced by twenty-one full term neonates with HIE were recorded. In the cohort, MAP was correlated with aEEG changes two and three hours after hypotension at with a correlation coefficient ( $\mathrm{r}$ ) of 0.454 and 0.477 . In the non-treated group, there was a significant correlation between MAP and all leads across the time period with $r$ ranging from 0.498 to 0.768 . Neonates with HIE stage III had a significantly stronger correlation between BP and aEEG over the time period compared to those with HIE stage II.

Conclusions There is a correlation between blood pressure and aEEG in neonates with HIE. This is especially evident in non-treated and the most encephalopathic neonates. These results may guide clinical practice in NICUs.

\begin{tabular}{l}
\hline 1083 THE HIGHLY SELECTIVE SIGMA-1 RECEPTOR AGONIST \\
PRE-084 REDUCES INFLAMIMATION-SENSITIZED \\
HYPEROXIA-INDUCED INJURY IN \\
THE DEVELOPING RAT BRAIN
\end{tabular}

doi:10.1136/archdischild-2012-302724.1083 